\title{
APÓS A PARTICIPAÇÃO: NOTA INTRODUTÓRIA
}

Adrian Gurza Lavalle

As pesquisas e os debates teóricos sobre a participação no Brasil registraram inflexão interessante ao longo da última década, e hoje configuram um cenário pós-participativo de indagações teóricas e empíricas que, em muitos sentidos, encontra-se à frente do estado da arte na literatura internacional. Subjaz a essa inflexão um processo histórico de alcance maior que transformou a participação em uma feição institucional do Estado no Brasil. Isto é, e independentemente das avaliações sobre o resultado desse processo, a participação, que nos anos 1960 a 1980 condensava a crítica dos atores sociais e de parte da academia perante os déficits de inclusão das instituições políticas e do crescimento econômico, bem como exprimia um reclamo de autodeterminação efetiva em face de partidos e intermediários políticos vários, tornou-se progressivamente, nos anos da pós-transição, parte da linguagem jurídica do Estado e atingiu patamares de institucionalização ímpares não apenas na história do país, mas em outras democracias. A participação, é claro, não perdeu seu registro simbólico original, mas adquiriu novo registro dominante porque inserida nos chamados 
"espaços participativos". Os atores sociais inseriram-se nesses novos espaços e a literatura acadêmica migrou com eles.

Trata-se de um cenário de pesquisa e teorização pós-participativo no sentido de a institucionalização e capilaridade territorial de arranjos participativos diversos, e a magnitude de atores sociais envolvidos nesses espaços, colocarem um conjunto de problemas impensável a partir do registro original da participação como demanda de inclusão e de autodeterminação. Assim, "pós” não remete ao mérito da participação em si, nem alude ao fato de as promessas associadas à ideia de participação terem se mostrado irrealizáveis, infundadas ou historicamente superadas - sentido amiúde associado ao prefixo "pós" -, mas atenta para o fato de as questões cruciais terem mudado após a participação, ou, com maior precisão, após a institucionalização em larga escala de arranjos participativos.

Se atores sociais encontram-se plenamente inseridos 14 em instâncias de controle sobre políticas públicas com trajetórias que já contam com pelo menos uma década de existência, não mais parece oportuno postular conexões normativas eventualmente plausíveis em vez de pesquisar os processos de participação em curso e de lhes extrair suas implicações mais gerais no plano da teoria. Sem enfrentar pressões ou desafios contextuais semelhantes, parte nada desprezível do debate internacional continua informado por compreensões da participação como engajamento informal que exprime reclamos de inclusão. Enquanto essas compreensões descansam facilmente em consensos normativos sobre o valor da participação, o cenário pós-participativo no Brasil induz a pesquisar questões que escapam do terreno confortável desses consensos, questões por vezes espinhosas que ampliam nosso conhecimento sobre processos de participação relativamente estáveis.

Grosso modo, o elenco de questões pesquisadas e teoricamente problematizadas nos últimos anos é passível de orga- 
nização em quatro frentes de trabalho. É uma ordenação sem qualquer pretensão de classificar de modo exaustivo ou sequer razoavelmente completo a produção acadêmica recente. $\mathrm{O}$ intuito é bem mais modesto, a saber, salientar a confluência de preocupações em torno de conjuntos de questões comuns. Primeiro, na medida em que os novos arranjos institucionais abrigam organizações civis e atores coletivos aos quais conferem não apenas reconhecimento como porta-vozes da sociedade civil, mas faculdades e investidura regulamentadas, esses arranjos operam, a rigor, como lócus de representação extraparlamentar. Vocalizar publicamente interesses ou falar em nome deles é prática comum das ações de protesto e das expressões de ação coletiva para as quais a sociologia política e a ciência política utilizaram outros conceitos que não o de representação, embora se tratasse de modalidade de representação de facto. Contudo, a vocalização de interesses sociais como incumbência associada a uma posição institucional constitui exercício de funções de representação política de jure. Assim, as inovações institucionais das últimas décadas emergem como caso extraordinário de pluralização da representação política. Isto porque o debate internacional sobre a emergência de novas formas de representação está centrado em modalidades qualificadas via de regra como informais. Quando olhados como instâncias de representação extraparlamentar, os espaços chamados de participativos ganham outra conotação: são parte de um processo de pluralização institucional da democracia, mas, simultaneamente, admitem questionamentos a respeito da legitimidade dos novos atores da representação. A pergunta pelo fundamento da legitimidade ou pelas eventuais práticas legitimadoras dos atores da sociedade civil que exercem funções de representação é hoje um debate de ponta no Brasil e pelo mundo afora, e no seu seio tem adquirido relevância crescente a questão da accountability da própria sociedade civil. 
Em segundo lugar, a descrição dos arranjos institucionais participativos como espaços conquistados de baixo para cima pela mobilização social, e nos quais se defrontam Estado e sociedade civil, tornou-se heuristicamente estéril para a compreensão do papel dos partidos políticos e governos na institucionalização e funcionamento regular desses arranjos. Sem entrar no mérito de quão acurada foi essa descrição retrospectivamente, o fato é que as instâncias participativas não operam como um "jogo de uma rodada só” e permitem aprendizagem e definição de estratégias. A estabilidade de arranjos institucionais como os conselhos gestores de políticas e, inclusive, a acumulação de experiências intermitentes como a do Orçamento Participativo (OP), reduziram a incerteza quanto ao alcance daqueles. De um lado, tornou-se claro que essas instâncias não realizariam a contento as expectativas mais ambiciosas dos atores sociais, de outro, houve aprendizagem por parte dos mesmos atores a 16 respeito da utilidade real das novas instituições. Lições pertinentes quanto às vantagens de ocupar essas instituições também foram extraídas por partidos políticos e governos. O olhar atento de pesquisadores para a racionalidade política dos diferentes tipos de atores nelas presentes vem desenhando um panorama diferente ao da descrição sintetizada acima: governo e partidos numa frente e sociedade civil em outra atuam de ambos os "lados da mesa", quer dizer, os primeiros disputam a representação da sociedade civil e os segundos procuram agir a partir da sua inserção na sociedade política. Assim, a divisão horizontal posta pela descrição do encontro e confronto entre sociedade civil e Estado perde as dinâmicas transversais que estruturam os espaços participativos. A indagação empírica e teórica da racionalidade e papel de governos e partidos em processos altamente institucionalizados e não plebiscitários de participação de cidadãos e atores coletivos é uma frente de trabalho inédita, sem paralelismos óbvios no debate internacional. 
Em terceiro lugar - e como qualquer instituição -, arranjos participativos, como os conselhos, não nasceram prontos. Foi preciso definir-lhes as rotinas, moldar-lhes os regimentos, mantê-los ativos e formar conselheiros experientes, e isso exigiu e continua a exigir tempo e energias consideráveis dos atores sociais. Logo, a realização da participação coloca a questão paradoxal dos eventuais efeitos deletérios sobre os atores nela engajados. Nesse caso, a literatura de movimentos sociais oferece as teses mais influentes sobre os efeitos da institucionalização: eles são negativos e implicam a desmobilização e extinção dos atores. Não é preciso gozar de uma sensibilidade aguda para reparar que a institucionalização em larga escala da participação no Brasil constitui uma anomalia para as teses consagradas nas teorias dos movimentos sociais. Sejam quais forem os efeitos - interrogação a ser empiricamente resolvida -, os movimentos engajados nesses espaços não definharam até a desaparição nem se burocratizaram ao ponto de sobreviverem reduzidos a um núcleo organizacional.

Por fim, quando considerado o grau de institucionalização e capilaridade territorial dos arranjos participativos, bem como o fato de a participação ser uma feição institucional do Estado no Brasil, o diagnóstico sistemático acerca dos efeitos reais desses arranjos sobre as políticas públicas ou sobre sua performance coloca-se como uma questão relevante para a tomada de decisões, para além de análises normativamente orientadas a respeito de quão efetivamente participativa é a participação - foco tradicional da literatura preocupada com avaliação nos estudos sobre espaços participativos. Trata-se de frente de trabalho ainda incipiente caracterizada por dificuldades metodológicas particularmente acentuadas, pois a aferição de efeitos impõe problemas de atribuição, isto é, de associação não espúria entre causa (participação) e efeito (performance da política, por exemplo). Nesse caso, o debate metodológico internacional 
sobre como equacionar problemas de atribuição é extremamente sofisticado, mas a avaliação sistemática dos efeitos dos arranjos institucionais participativos tinha recebido atenção insuficiente na literatura nacional.

Este número da Lua Nova oferece um panorama da produção acadêmica própria desse cenário pós-participativo, concentrando-se majoritariamente nas duas primeiras frentes e, em menor medida, na terceira. A quarta frente não será abordada pelos artigos que compõem o dossiê "Após a participação"1. O primeiro conjunto de trabalhos examina criticamente preocupações de ponta na teoria política e as conecta com os processos de pluralização da representação ocorridos no país e pelo mundo afora. $\mathrm{O}$ artigo de Luis Felipe Miguel examina duas classes de argumentos de representação que ganharam influência na crítica às teorias institucionais da representação e na compreensão da multiplicação de modalidades extraparlamentares de representação, 18 a saber, aqueles centrados em identidades ou na política da presença, bem como aqueles que caracterizam a representação como ação de vocalização, isto é, de advocacy. De modo arguto, o autor mostra que a despeito do seu caráter crítico e suas pretensões de compensação quanto à inclusão política de grupos e argumentos minoritários, essas propostas não oferecem resposta satisfatória ao problema da igualdade política e tendem a desvalorizar os mecanismos tradicionais de accountability e autorização. Uma proposta capaz de incorporar satisfatoriamente a questão da igualdade política teria que outorgar centralidade ao papel dos interesses na representação e aos processos de formação de interesses. De fato, a multiplicação de balanços teóricos assinalando os limites

\footnotetext{
${ }^{1}$ O leitor pode se beneficiar, a esse respeito, da leitura de Avritzer (2010), que expõe os resultados de um dos projetos mais amplos de avaliação já realizados no país. Ainda no prelo, o volume organizado por Roberto Pires, que será publicado pelo Ipea e que deverá se intitular "A efetividade das instituições participativas no Brasil” também pode ser útil para o leitor.
} 
da representação eleitoral e a busca de critérios de legitimidade satisfatórios para a pluralização da representação política acabaram por conferir renovada relevância teórica ao conceito de accountability e à política da transparência como condição do primeiro. Fernando Filgueiras reconstrói criticamente a aposta da teoria política em ambas - transparência e accountability -, mostrando de modo persuasivo que, malgrado sua função de garantia normativa da democracia, esta última carece de fundamentação normativa própria, a qual, é claro, deve ser procurada para além da definição procedimental formal de accountability. $\mathrm{O}$ autor desenvolve uma proposta com o intuito de fornecer esse substrato normativo explorando a relação entre esfera pública e accountability.

Não apenas a accountabilty ganhou inusitado protagonismo no elenco de conceitos chave da teoria política debruçada sobre as possibilidades de aprimoramento das democracias. Conforme mostrado no artigo de Gurza Lavalle e Isunza Vera, a trama da crítica democrática sofreu deslocamentos inesperados e tanto a representação quanto a participação perderam suas posições reciprocamente polares no campo da teoria democrática. Os autores examinam as condições históricas e as especificações teóricas que animaram tal polaridade no contexto da Guerra Fria e esboçam a nova posição da participação, representação e accountability na crítica democrática. Nesse movimento, e graças à dissociação conceitual entre representação política e governo representativo, as teorias da representação tornaram-se fonte de crítica interna à democracia invertendo sua posição tradicional de flanco de defesa de concepções minimalistas procedimentais. Se a despolarização da relação entre participação e representação está posta pela institucionalização de modalidades extraparlamentares de representação exercidas por atores sociais, e é conceitualmente concebível pelos deslocamentos teóricos apontados, isso não implica, como mostrado em análise instigante por Lígia Lüchmann, 
que seu exercício seja automaticamente compatível com os repertórios de atuação desses atores. Com efeito, a autora leva em consideração a variação organizacional dos atores envolvidos na pluralização da representação e examina a representação - do ponto de vista do ator - como uma prática que tensiona e ressignifica outras práticas nos repertórios desses atores. A questão de fundo é a legitimidade e a possibilidade de se conectar práticas de representação com práticas de participação de modo induzir a responsividade dos atores no exercício de práticas de representação extraparlamentar.

A segunda parte deste número da Lua Nova constitui, pela sua riqueza e originalidade, uma verdadeira rajada de ar fresco no campo de estudos sobre instituições participativas no Brasil, e sobre os atores sociais voltados para incidir nelas. Assim como a primeira parte lida com referentes empíricos claros, embora orientada ao campo da teoria política, a segunda encontra-se comprometida com a pesquisa 20 empírica e trabalha com referentes teóricos parcimoniosamente especificados. Luciana Tatagiba e Karin Blikstad oferecem analise preciosa das eleições para o conselho municipal de habitação, mostrando os alinhamentos transversais entre governo, partidos e atores sociais - o movimento de moradia. $\mathrm{O}$ valor dos resultados apresentados por ambas as autoras reside em rastrear o processo e motivações que levaram à reformulação das regras eleitorais optando por privilegiar uma composição plural do conselho mediante a adoção de listas fechadas e proporcionalidade. O governo e o movimento amargaram os custos de permanecerem fora do conselho como decorrência de eleições pretéritas. Assim, aprenderam a coordenar seus interesses. A rigor, as novas regras não apenas excluem candidaturas avulsas, mas entregam o controle da composição do conselho ao governo e ao movimento de moradia, e alinham-na com a clivagem partidária que ordena as eleições majoritárias no município de São Paulo e no país, a saber, PSDB (DEM) e PT. 
Wagner de Melo Romão e Luciana Martins de Souza atentam também para a racionalidade política dos principais atores envolvidos em arranjos participativos, mas focam a atenção no funcionamento do OP. O primeiro autor levanta uma série de ressalvas em face das caracterizações tradicionais do OP como criatura criada e animada pelas dinâmicas da sociedade civil, pois perde-se de vista a relação entre esses espaços e a sociedade política. $\mathrm{O}$ argumento é colocado em jogo mediante a análise das trajetórias e motivações dos conselheiros no OP de Osasco. As evidências corroboram o argumento: a maior parte dos conselheiros encontra-se inserida na sociedade política, em posições periféricas ou, nas palavras do autor, nas "franjas" da sociedade política. O OP seria assim um canal de visibilidade e ascensão nas trajetórias desses conselheiros. Em perspectiva semelhante, a segunda autora defende que o alcance e continuidade do OP são insuficientemente compreendidos a partir da "tradição associativa local", do "desenho institucional" ou da "vontade política" do executivo, variáveis centrais da literatura dedicada a perscrutar as condições de sucesso dessa instância participativa. Exame comparativo da implantação do OP nos municípios paulistas de Matão, Rio Claro e São Carlos revela que a continuidade e alcance se deve aos conflitos locais entre Executivo, Legislativo e partidos no âmbito do governo municipal, bem como à capacidade de encontrar mecanismos distributivos capazes de agradar as partes e de lhes aparar as animadversões contra o OP.

A institucionalização de arranjos participativos em larga escala trouxe para o centro da atenção os novos papéis desempenhados por atores sociais e suas funções no controle societal de políticas públicas; também induziu as agendas acadêmicas a privilegiar certos atores, precisamente aqueles em condições de ocupar as novas posições institucionais. Porém, as novas ênfases têm negligenciado a escala microterritorial e os atores que atuam nos bairros como agentes empenhados 
no aprimoramento da provisão de serviços públicos. A esse respeito, o artigo de Amâncio, Serafim e Dowbor é original e surpreendente. As autoras apresentam resultados de pesquisa comparativa em 45 microrregiões de baixa renda do município de São Paulo, desenhada para levantar as ações de controle societal realizadas em torno da saúde básica e da assistência social. Seus resultados erguem-se contra prognósticos plausíveis e passíveis de serem derivados a partir das literaturas que têm estudado as políticas setoriais, os espaços participativos e os atores sociais vinculados às trajetórias setoriais. O plano microterritorial apresenta logica própria, com atores engajados em repertórios diversos de controle societal, mas não orientados setorialmente, e tampouco conforme os padrões da distribuição geográfica dos grandes movimentos urbanos. Por fim, o artigo de Euzeneia Carlos enfrenta a questão dos efeitos da inserção dos movimentos sociais em arranjos participativos altamente institucionalizados. O interlocutor obriga22 tório, como mencionado acima, são as teorias dos movimentos sociais e sua sinonímia entre institucionalização, de um lado, e ossificação organizacional, alienação participativa e desmobilização, de outro. A autora apresenta resultados de pesquisa comparativos de dois movimentos sociais oriundos do município de Serra-ES, examinando minuciosamente as mudanças registradas nas dimensões organizacional, relacional e discursiva da ação coletiva desses movimentos. Registraram-se, nessas três dimensões, mudanças no sentido do incremento da complexidade organizacional, da ampliação de expedientes de ação formalizada, do adensamento de vínculos com instituições governamentais e do discurso de compreensões contenciosas ou de confrontação da relação com o governo para entendimentos mais cooperativos. Contudo, os padrões de ação coletiva encontrados pela autora são híbridos, isto é, articulam essas mudanças com expedientes participativos, vínculos com outros atores da sociedade civil e uma semântica de contestação. 


\section{Adrian Gurza Lavalle}

é professor do Departamento de Ciência Política da USP e pesquisador do CEM-Cebrap.

\section{Referências Bibliográficas}

AVRITZER, L. (2010). A dinâmica da participação local no Brasil. São Paulo:

Cortez. 